تحليل متوسط الأجيال لتقدير بعض المعايير الوراثية للحاصل ومكوناته لأربعة تضريبات من الأرة الصفراء

$$
\text { بنان حسن هادي }
$$

bhd.1970@yahoo.com

$$
\text { قسم المحاصيل الحقلية - كلية الزراعة- جامعة بغداد }
$$

المستخلص

نفذت تجربة حقلية في حقول قسم المحاصيل الحقلية - كلية الزراعة - جامعة بغداد للمواسم ربيع وخريف 2009 و2010 ربيع و 2011 و خريف 2013 بهدف معرفة المقار النسبي لمكونات التغاير الوراثي وأثكال التداخلات التفوقية باستخدام تحليل متوسط الاجيال

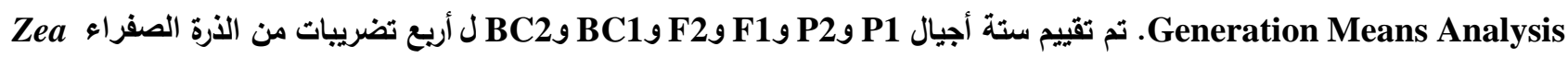

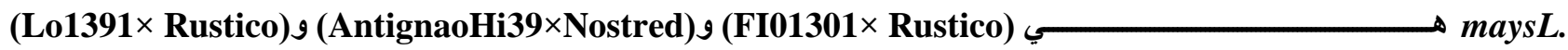
و(Rusticocangini×Rustico) بتصميم القطاعات الكاملة المعثاة RCBD باريع مكررات لصفات الحاصل ومكوناته. اظهرت النتائج فروق معنوية بين الأجيال لكل الصفات المدروسة للتضريبات الاربع. تفوق الجيل الاول F1 باعطاء اعلى متوسط لكل الصفات المدروسة



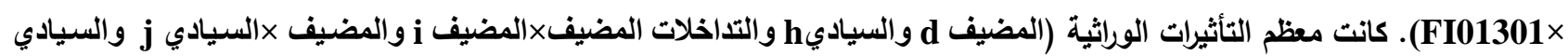
xالسيادي l) معنوية للتضريبات الأربعة والتي اختلفت باختلاف الصفة والتضريب. اشارة الى اهمية التاثيرات المضيف والسيادي والتفوق كفعل جيني تسيطر على صفات الحاصل ومكوناته في الأرة الصفراء. الا ان التغاير السيادي كان اكثر أهمية من التغاير المضيف في صفة

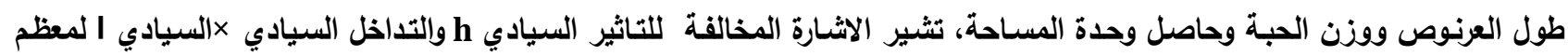
الصفات ولمعظم التضريبات السى وجود فعل التفوق المضـاعف Duplicate Epistasis. كمـا ظهر التفوق التكميلي-Epistasis. omplementary لصفة حاصل وحدة المساحة للتضريبين (FI01301× Rustico) و) AntignaoHi39×Nostred) ولصفة وزن الحبة للتضريب (Lo1391×Rustico). نستتتج مما تقدم ان الفعل الجيني المضيف وغير المضيف يسيطر على توريث صفة الحاصل ومكوناته. يوصي باستخدام طريقة الانتخاب التكراري المتبادل لتحسين الصفات. كلمات مفتاحية: المضيف،غير المضيف ، الفعل الجيني، الغزارة الهجينية.

The Iraqi Journal of Agricultural Sciences - 47(1): 246-258, 2016

Hadi

\title{
GENERATION MEAN ANALYSIS FOR ESTIMATION SOME GENETIC PARAMETERS FOR YILD AND YIELD COMPONENTS IN FOURE MAIZE CROSSES.
}

\author{
B. H. Hadi
}

Instructor

bhd.1970@yahoo.com

\section{ABSTRACT}

Crop Sciences Dept - College of Agriculture-University of Baghdad

A field experiment was conducted at the field of Field Crop .Dept., College of Agric $\backslash$ Univ.of Baghdad. spring and fall seasons of 2009, 2010 , spring of 2011 and fall of 2013 in order to know the relative magnitude of the genetic variation component and interactions forms of epistasis using Generation Means Analysis of maize (Zea mays L.) . Six generations P1 , P2 , F1, F2, BC1 and BC2 for four crosses (FI01301 $\times$ Rustico), (AntignaoHi39 $\times$ Nostred ), (Lo1391 $\times$ Rustico) and ( Rusticocanginix Rustico) were evaluated by using randomized complete block design( RCBD) with four replications for grain yield and its components. The results showed significant differences between the generations of the four crosses. The first generation superiority and gave the highest mean for each of the traits of four crosses. The highest hybrid vigor and heterosis percent to for unit area grain yield (ton $\backslash$ ha) $\mathbf{1 2 1 . 8 \%}$ and $\mathbf{1 2 6 . 9 2 \%}$ for cross( FI01301 $\times$ Rustico ). Most of the genetic effects (d additive , dominance $h$, additive $\times$ additive $i$, additive $\times$ dominance $j$ and dominance $\times$ dominance $l$ ) were significant for all crosses . This revealed the importance of the dominance, additive and epistasis effects as genetic actions controlled in yield inheritance and its components in maize. But the dominance variation was more important than the additive variation in the ear length, grain weighte and yield unit area, disagreement signal indicate the existence of an act of the dominance $h$ and dominancex dominance 1 of most studied traits duplicate epistasis. Supplementary superiority also appeared to Epistasis complementary of crosses $($ FI01301 $\times$ Rustico) and (AntignaoHi39 $\times$ Nostred) and grain weight in cross $($ Lo1391 $\times$ Rustico $)$. It can be conclude that the additive and non-additive gene action control the in heritable yield and its component . It is recommend using the method of reciprocal recurrent selection(RRS) to improve yield and its components .

Key words: Additive, non additive ,gene action ,hybrid vigor 
عن التربيـة الذاتيـة للهجن الفرديـة المتميزة (F2 وF3) التي تعد مصدرا مهما للتراكيب الوراثية الجديدة ولاسيما أن الجيل الثاني F2 هـو الجيـل الذي تحدث فيسه أقصسى الانعزالات

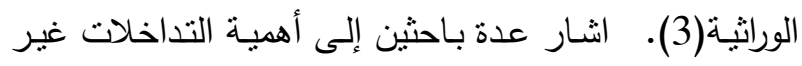

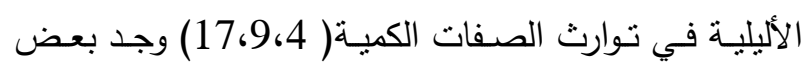

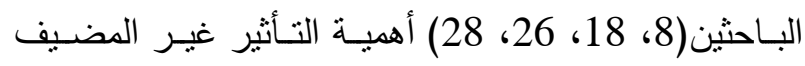
لبعض صفات الذرة الصفراء. درس Alam وآخرون (2) عدد البد صفوف العرنوص وأثنار الى أهمية التأثنر المضيف في هذه وأهن الصفة، وبينت نتائج Kumer وآخرون (12) أهميـة كـلا

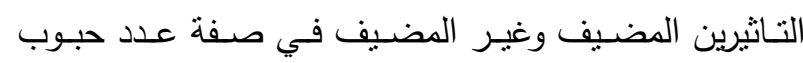
الصــف و يعـود السـبب فـي ذلــك الـى الطبيعـة الوراثيــة

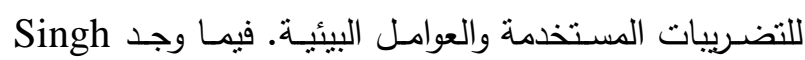


التكميلي وهم في توريث صفة الحاصل. بين Ravikant وآخرون (17) أن تأثيرات جينات التقوق لها الأثر الأكبر في توريث صفات الحاصل

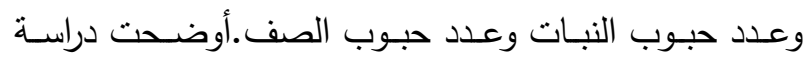

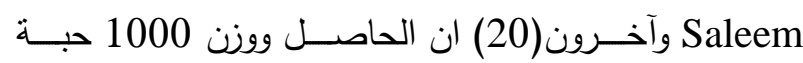
تحكمها جينات السيادة الفائقة over dominance ، وحصل ان Kumar

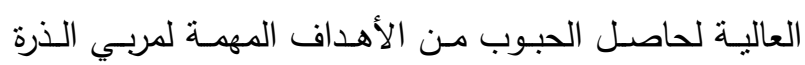
الصفراء والتي يمكن الحصـول عليها من تضـريب سـلالات نقية تمتاز بالتباعد الوراثي (1). حصل عدة باحثين على قوة

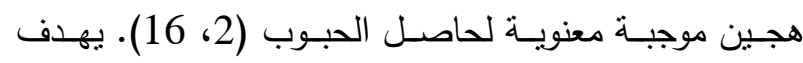
البحث الى تحديد المقدار النسبي لتأثيرات ازواج الجينات التي

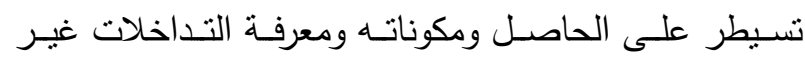

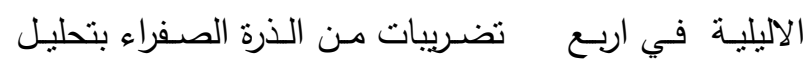

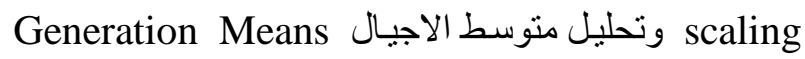
Analysis

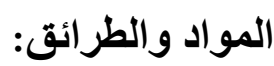

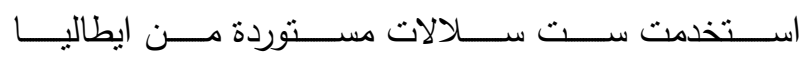
AntignaoHi39 $\quad$ FI01301 Rusticocangini

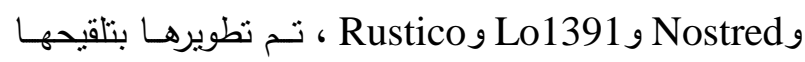
ذاتيا لثلاث اجيال بهدف زيادة النقاوة الوراثية في ربيع وخريف

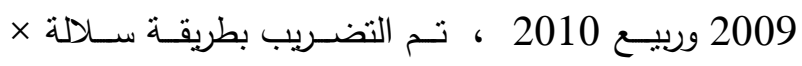

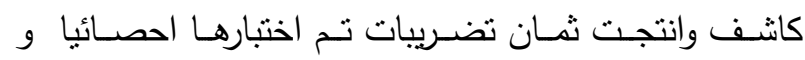

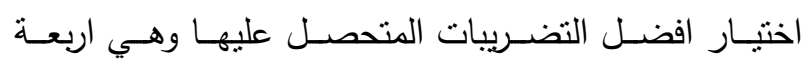

المقدمة

يعد تطوير الهجن والأصناف الهدف الرئيسي في برامج تربية

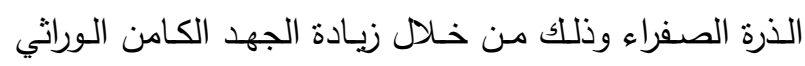
للحاصل genetic potential yield. بذلت جهود كبيرة

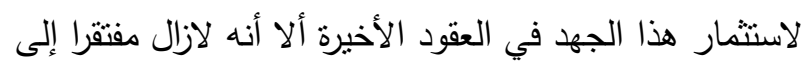

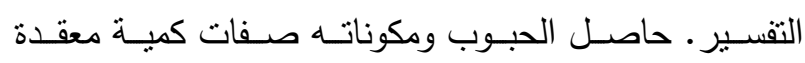

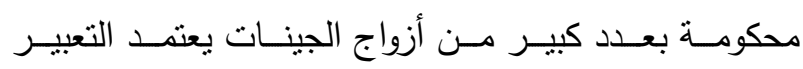

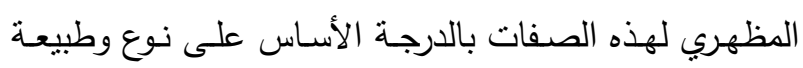

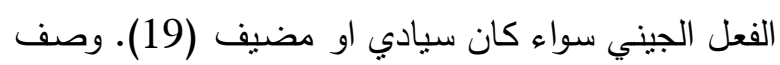

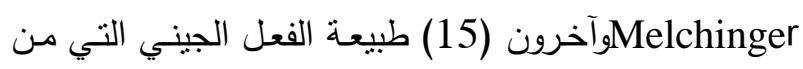
خلالها يتمكن مربو الذرة الصفراء من الوصول إلى الطريقة

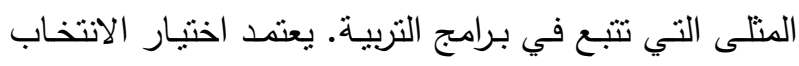

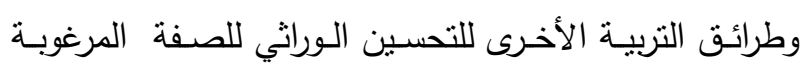

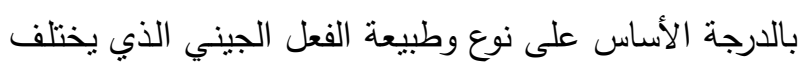


المسـتخدمة(7). أثثـار Gambel (6) ان تقـدير التـأثيرات الوراثيـة يسـاعد مربـي النبـات على اختيـار الطريقـة الأكثر

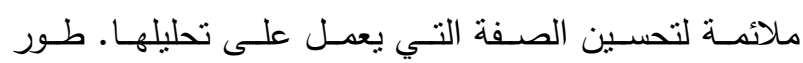

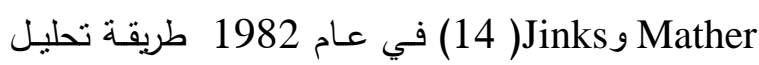
متوسط الأجيال Generation Mean Analysis لتحديد التأثيرات الوراثية للصفات التي تحت تأثير ازواج متعددة من الجينات Poly genes traits وهي الأكثر مقدرة على تقدير تأثنيرات التفوق الجينات

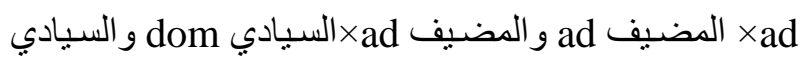


(24). تعمل اغلب طرائق التربية على زيادة حاصل الحبوب

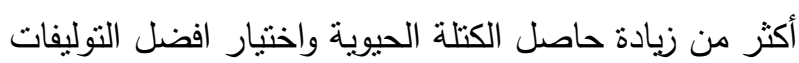

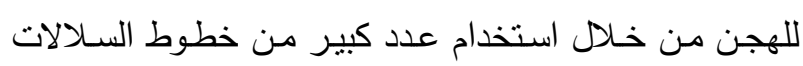



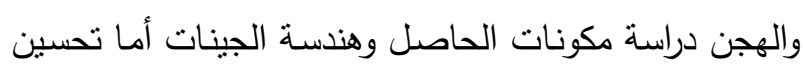
الأصـناف فيتطلب فهم الآليـة التي تسبطر على التى الحاصلـل

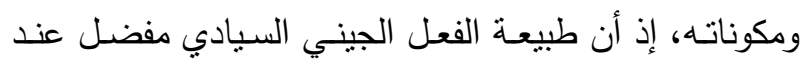



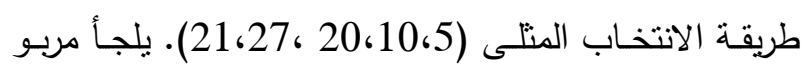

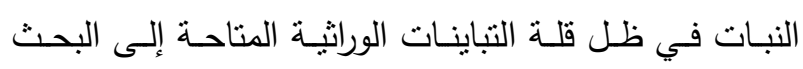
ضمن المادة الوراثية المتوافرة لديهم ولاسيما الانعزالات الناتجة 
$\mathrm{D}=2 \overline{F 2}-\overline{B 1}-\overline{B 2}$

ان معنوية A و Bتشير الى وجود كل انواع التداخلات غير الاليلية فيما تشير معنوية C الى معنوية التداخل السيادي ج

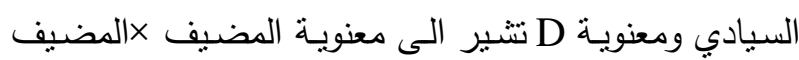
ومعنوية كلا من C و D تشير الى معنوية كليهما.

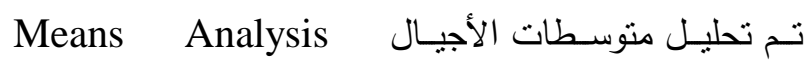
Generation حسب ندوذج Mather و Jinks (14) وفق $Y=m+\alpha[d]+\beta[h]+\alpha 2[i]+2 \alpha \beta[j]+\beta 2[1]$



منوسط الاجيالY= متوسط كل من الخطوط الممكنة المنماثلة والتي =m =m

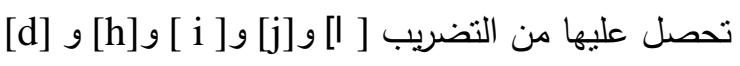
صافي التأثيرات المباشرة المضيف والسيادي والمضيف xالمضيف و المضيف ×السيادي والسيادي ×السيادي .

تم حسابها حسب ماجاء به Singh و (24)Chaudry $\mathrm{m}=$ mean $=\overline{F 2}$

$\mathrm{d}=$ Additive effect $\mathrm{t}=\overline{B 1}-\overline{B 2}$

$\mathrm{h}=$ Dominance effect $=\overline{F 1}-4 \overline{F 2}-0.5 \overline{P 1}$ $.5 \overline{P 2}+2 \overline{B 1}+2 \overline{B 2}$

$\mathrm{i}=$ Additive $\times$ Additive type of gene interaction $=2 \overline{B 1}+2 \overline{B 2}-4 \overline{F 2}$

$\mathrm{j}=$ Additive $\times$ dominance type of gene action $=\overline{B 1}-0.5 \overline{P 1}-\overline{B 2}+0.5 \overline{P 2}$

$1=$ dominance $\times$ dominance type of gene action $=\overline{P 1}+\overline{P 2}+2 \overline{F 1}+4 \overline{F 2}-4 B 1-4 \mathrm{~B} 2$

حسبت الاخطاء القياسية :

$\mathrm{SE}(\mathrm{m})=(\mathrm{Vm})^{0.5}, \mathrm{SE}(\mathrm{d})=(\mathrm{Vd})^{0.5}, \mathrm{SE}(\mathrm{h})=(\mathrm{Vh})^{0.5}, \mathrm{~S}$ $\mathrm{E}(\mathrm{i})$

$=(\mathrm{Vi})^{0.5}, \mathrm{SE}(\mathrm{j})=(\mathrm{Vj})^{0.5}, \mathrm{SE}(\mathrm{l})=(\mathrm{Vl})^{0.5}$,

كمـا حسـبت قـوة الهجـين hetrosis و والغـزارة الهجينيـة \% \% حسب المعادلتين الاتيتين : $\mathrm{H} \%(\overline{M P})=(\overline{F 1}-\overline{M P}) / \overline{M P}$ H.V\% $(\overline{B P})=(\overline{F 1}-\overline{B P}) / \overline{B P}$

تم تحليل البيانات في برامج Software

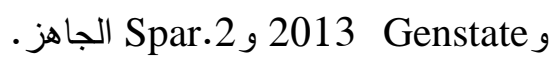

\section{النتائج والمناقشة}

P1 نظرا لوجود فروق معنوية بين متوسطات الأجيال الستة


(AntignaoHi39×Nostred)و و

(FI01301×Rustico)
(FI01301× Rustico)

(Lo1391× Rustico)و (AntignaoHi39×Nostred) و (Rusticocanginix Rustico) وهـي التي تفوقـت (An) بالحاصل العالي وصفات النمو الجيدة تمت. زراعة F1 في ربيع 2011 مع ابائها وضربت رجعيا مع بذور BC1 و BC2 بالتتابع، كما لقحت نباتات

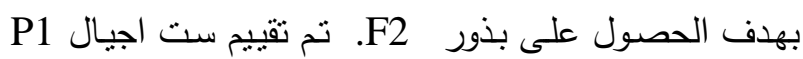


المذكورة اعـلاه في الموسم الخريفي 2013/7/17 بتصميم القطاعات المعثاة الكاملة RCBD باربعة مكررات في حقول

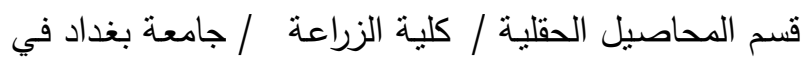
أبي غريب. تمت زراعة كل تركيب وراثي على اربعة مروز بطول 5 متر والمسافة بينها 0.75 م وبين نبات واخر 0.25

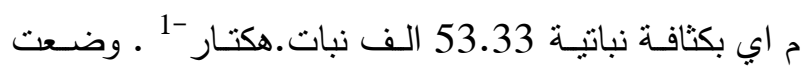
ثلاث بذور في كل جورة وخفت الى نبات واحد بعد 15 يوم

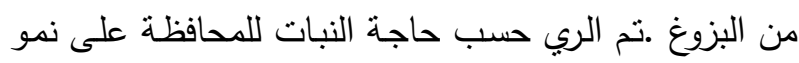

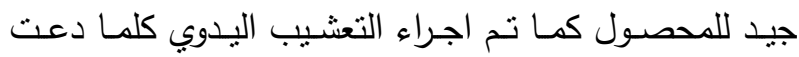
الحاجـة.تمت اضـافة سماد السوبر فوسفات الكالسيوم بمعدل

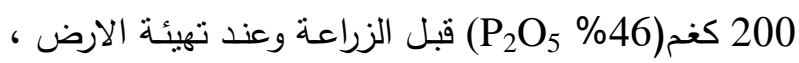
كما اضيف السماد النتروجيني على شكل يوريا بمعدل 400 كغم .هكتار -1 (N \%46) ،على ثناث دفعات عند الزراعة وعند مرحلة الاستطالة وقبيل التزهير .كما استخدم الديازينون المحبب بمعدل 8 كغم اهكتار للوقايـة من الإصـابة بحشـرة

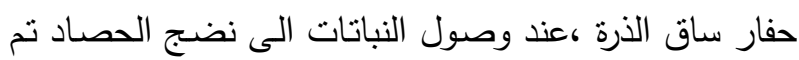

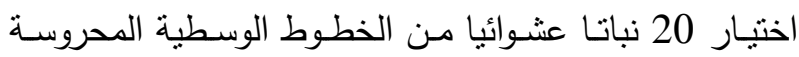


نباتـا من F2 ـ تمت دراسة صفات طول العرنوص الرئيسي وعدد صفوفه وعدد حبوب الصف وعدد حبوب النبات ووزن


هكتار .تم تحليل منوسطات الاجيال السـتة و F2 و BC1 BC2 للتصميم المذكور للصفات السبع اعلاه

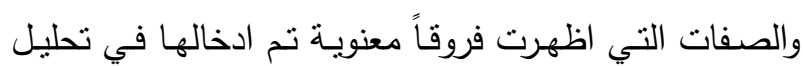

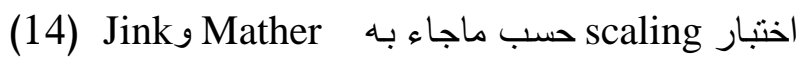
بحساب مقدار كل من A و B و و و وتبايناتها المعادلات الآتية:ا $\mathrm{B}=2 \overline{B 2}-\overline{P 2}-\overline{F 1}$ $\mathrm{C}=4 \overline{F 2}-\overline{2 F 1}-\overline{P 1}-\overline{P 2}$ 
السيادي هو المسيطر على صـفة طـول العرنوص، تجدر الإثارة إلى ان التأثيرات السيادية كانت موجبة بينما التأثيرات المضيفة سـالبة لكل التضـريبات باستثناء التضـربب الاخير

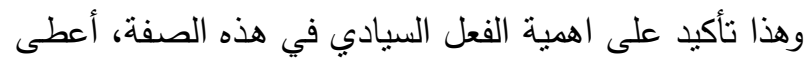

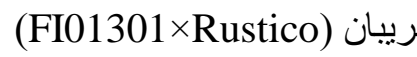
التض وها تاك و (AntignaoHi39×Nostred) تأثير سيادي موجبا اعلى (A) من m ونأثير التداخل السيادي ×السيادي سالب مما يوضح وجود التقوق المضاعف Duplicate Epistasis لذلك فإن

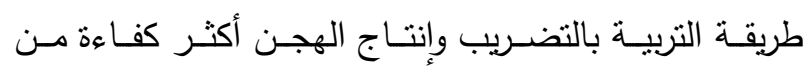

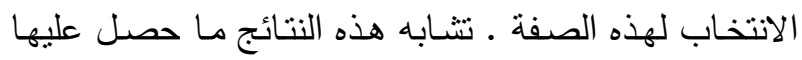



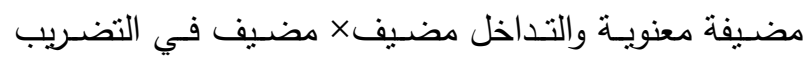
و التضـــ (AntignaoHi39×Nostred) يشير الى وجود بعض من (Rusticocanginix Rustico) الفعل الجيني المضيف يعمل أيضا على نوريث هذه الصفة

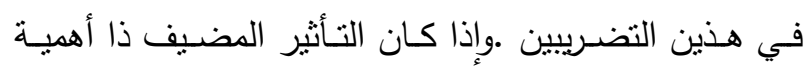
ثانوية أو يسهم بشكل ثانوي بالتغاير الكلي فان هذا يؤكد على الثى

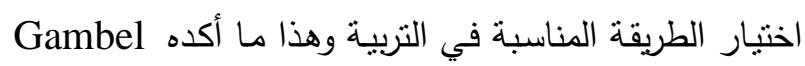

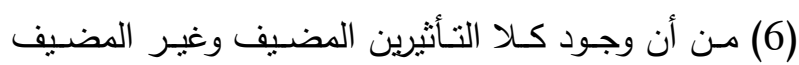


لأنها (RRS) Reciprocal Recurrent selection تكون الأكثر كفاءة من RGCA) لأنها نأخذ فقط التأثيرات السيادية وهي اكثر كفاءة من RSCA التي تأخذ التأثنر المضيف فقط. أعطى التضريبان الأول والثاني شكل التفوق

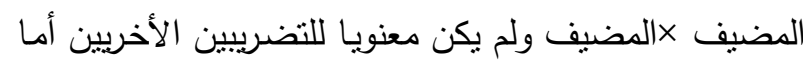
الثكل الآخر مـن التفوق المضيف xالسيادي فكان معنويا للتضـريبين الثاني والرابع وغير معنوي للتضـريبين الاخريين فيمـا أعطى التضـريبان الأول والثاني تـأثنير معنويـا سـالبا.

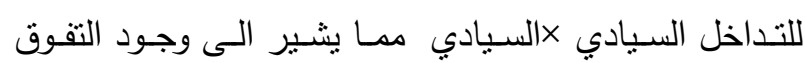
المضاعف.

\section{عدد صفوف العزنوص}

تشـير بيانـات جدول 1 إلى اختلاف متوسـط عدد صـفوف العرنوص الذرة الصفراء للجيل الأول باختلاف التضريبات، كان عدد الصفوف في التضـريب (FI01301×Rustico)

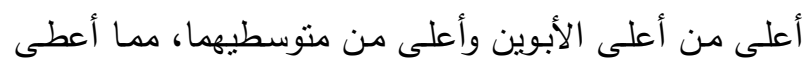

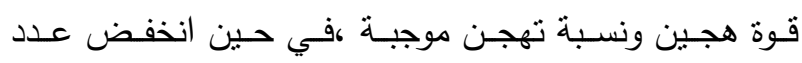

و و (Rusticocangini×Rustico) فقد (Lo1391×Rustico)و تم إخخالها في تحليل اختبـار scaling وتحليـل منوسطات

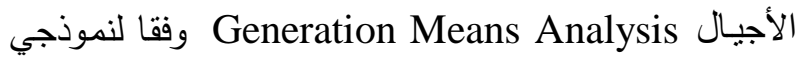
6 Models Parameter المعايير الأربعة والمعايير الستبـة .(24) 4 \& طول العزنوص تشير بيانات الجدول 1 الى تفوق الجيل الأول F1 Fلى ألى

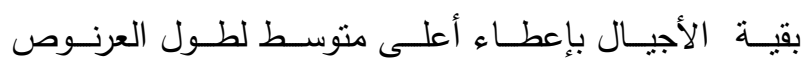

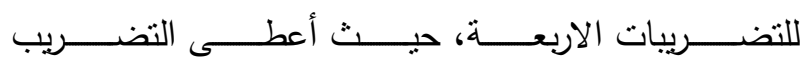
\% أعلى قـوة هجين بلغت

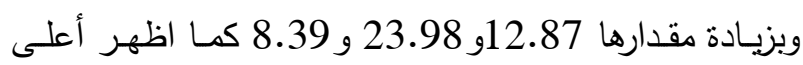

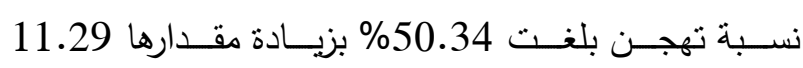

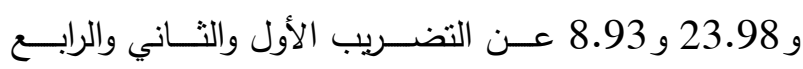




للفعل الجيني لتفوق منوسط الجيل الاول لهذا التضريب بطول


حصل عليه Shahrokhi وآخرون(21). تشير نتائج اختبار

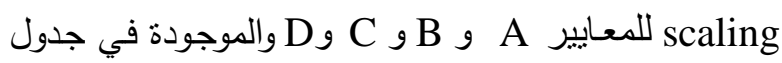
2 إلى وجـود تأثنرات معنويـة للتنداخلات غير الاليليـة التي وني تسبطر على التغاير الوراثي بين الأجيال الستة لصفة طول

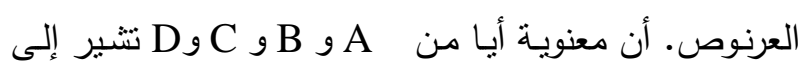


الذي يبين مكونات التباين الوراثي وفق نموذج المعايير الستة

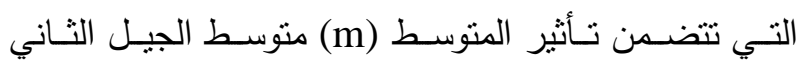

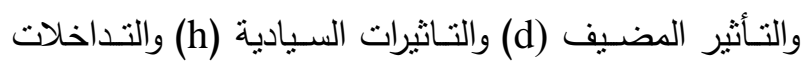
المضيف ×المضيف (i) والمضيف ×السيادي (j) والسيادي

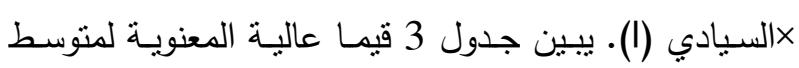


التباعد الوراثي بين السـلالات المستخدمة، كما يبين الجدول ذاته ان الفعل الجيني السيادي هو المسؤول عن هذه الصفة لهن

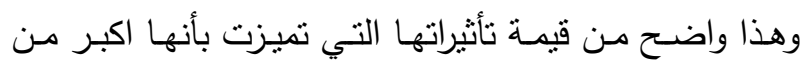

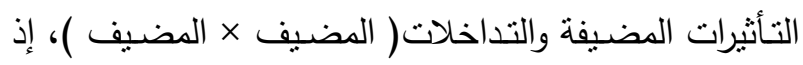
بلـغ التـأثنير السـيادي 17.25 و 18.94 و 11.77 و 14.83

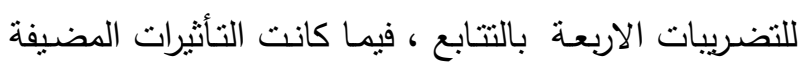

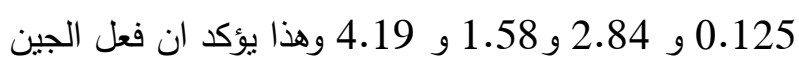


مسن قـوة الهجـين وقيمـة الـتهجن الموجبــة والعاليــة لكـلـ التضريبات ، ويشير هذا الى وجود تغايرات وراثيـة عاليـة ،



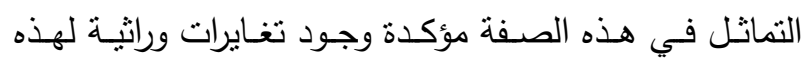
الصفة في ابائها ـ كانت أعلى قوة هجين ونسبة تهجن لعدد وجدائرد حبوب الصف للتضريب (FI01301×Rustico) 74.01) و76.78 وهذا يشير إلى أن صـفة عدد حبوب الصف

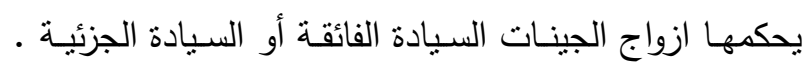

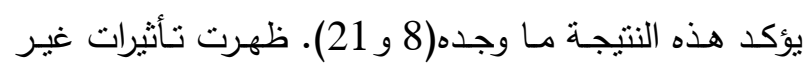

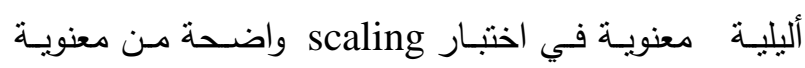

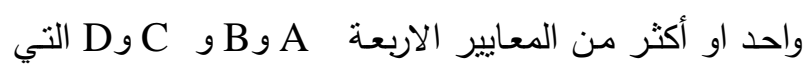


التأثنرات التفوقية نعود إلى جدول 3 الذي يشير الى وجود

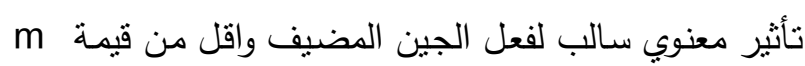
للتضريبات الأربع وهذا يشير إلى صغر مساهمة فعل الجين


السلالة P1 جيدا في التضريبات فان معظم تقديرات المضيف



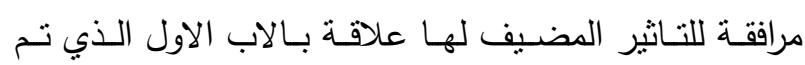

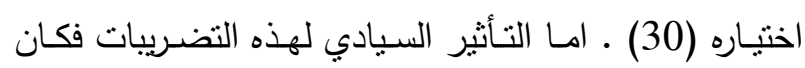

معنويا موجبا للتضريب( (AntignaoHi39 × Nostred) (Rusticocangini × Rustico) و (Lo1391× Rustico)

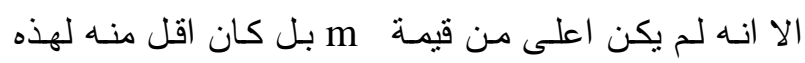

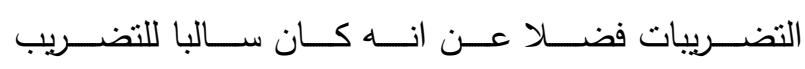



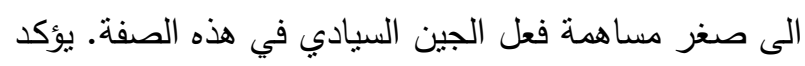

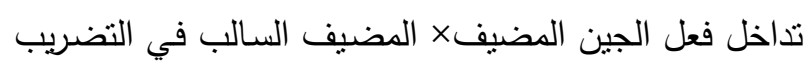
وغير المعنوي في بقية التضريبات (FI01301×Rustico) قلة اسهام فعل الجين المضيف في التأثير في هذه الصفة .

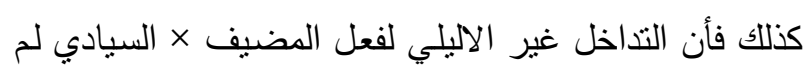

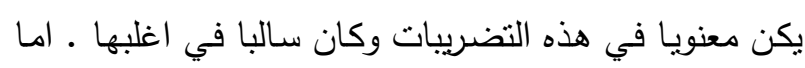

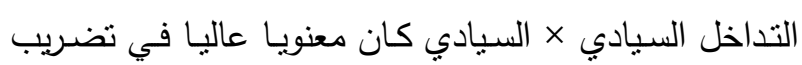
واحد فقط هو (FI01301×Rustico) ولم يكن معنويا في

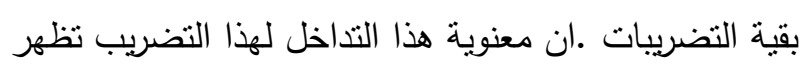

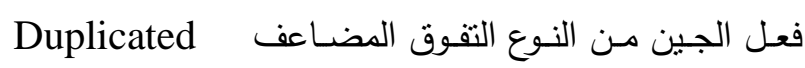
Epistasis
الصفوف عن أعلى الأبوين وعن متوسطيهما في التضريبات



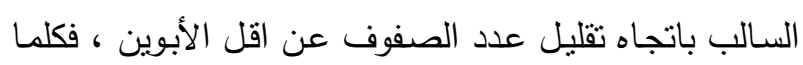
كان الاختلاف الوراثي بين الأبوين (متباعدة وراثيا) اكبر كلما

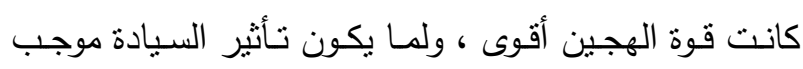


توريـث الصـفة للأجيـال المدروسـة.أظهرت بيانـات جدول 2 لاختبـار scaling وجـود تأثثيرات تفوقيـة معنويـة لصففة عدد

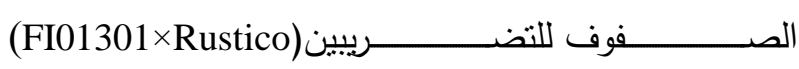
و) ولـم يظهـر تـأثنيرا تفوقيـا معنويا للتضريبين الأخريين. كما تؤكد بيانات جدول 3 ذلك بط بعدم معنويـة التداخلات غير الاليليـة للتضـريبين المـكورين

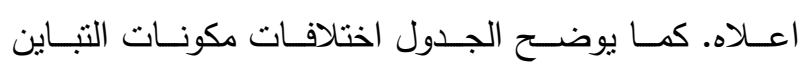
الور اثيس و d و و و وز و ألهذه الصفة باختلاف التضريبات

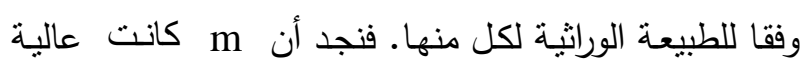

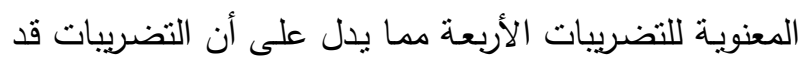
نتجت عن سـلالات منباعدة ومختلفة في الجينات المسؤولة عن هذه الصفة، ان التأثيرات المضيفة d للتضريبات الثنلات

(AntignaoHi39×Nostred) (FI01301×Rustico)

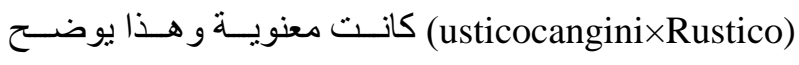
وجـود تـأثنير لفعـل الجـين المضـيف في السبطرة على هذه

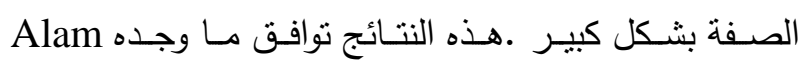

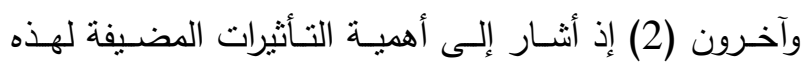

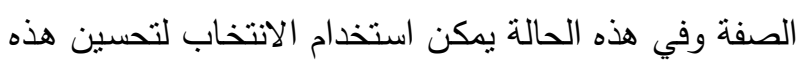

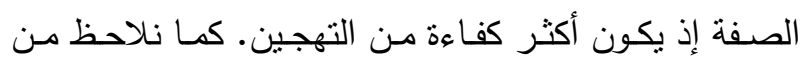


تأثثرات سيادية وتداخلات مضيف ×مضيف ومضيف دميادي

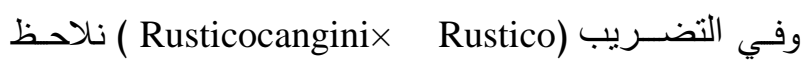
تأثيرات التـداخلات مضـيف جسـيادي ، وهـذا يوضــح أسـهام

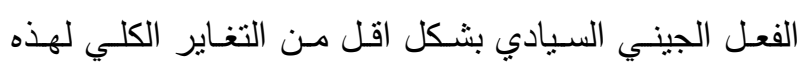

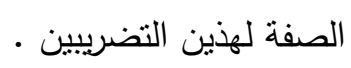
عدد حبوب الصف يتضـح من جدول 1 ان هنـاك تغـايرات ورانيـة واضحة بين

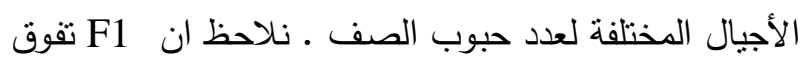
باعطاء اعلى عدد حبوب للصف للتضربيات الاربعة وكانت اعلى من أعلى الأبوين واعلى من متوسطيهما وهذا واضح 
وموجبـا غيـر معنـوي للتضـريب (Lo1391×Rustico) امـا


معنوي لاثنين من التضريبات (AntignaoHi39×Nostred)

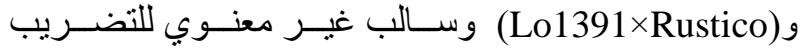
و امـا الثكل الاخر من التفوق السيادي×السيادي فكان موجباً معنوياً عاليا في التضريب(FI01301×Rustico) فقط وكان اعلى من قيمة m أيضـا ـ اما تأثثر السيادي ×السيادي في التضـريب (AntignaoHi39×Nostred) فكـان موجبـا غيـر معنـوي وسـالبا عـالي المعنويـة واعلى مـن m في التضـريب m وسالب عالي المعنوية لكنه اقل من (Lo1391×Rustico) في التضريب Rusticocanginix Rustico) نستتتج من هذه البيانات لهذه الصفة ان هذه التضريبات قد اظهرت تقديرات معنويـة لتأثنر فعل الجين التفوقي لواحد او اكثر من اشكال التفوق الـثلاث .وان اثتـين مسن التضـريبات اظهـرت تقدير

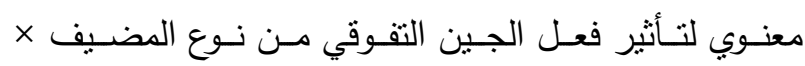
المضـيف ،كمـا وجـدت تقديرات معنويـة مسن نـوع السـيادي

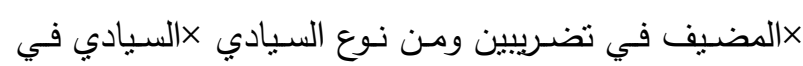

$$
\text { ثناث تضريبات . }
$$

نستوضـح مـن بيانـات جـدول 1 انخفـاض الخطـأ القياسـي للتضــربيات التي تـم دراسـتها مدـا يثـير الـى تماثتل نباتاتهـا وانخفاض التغاير الوراثي فيها لوزن الحبة . بدليل انخفاض

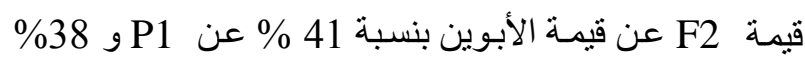
عن P2 وكذللك تقارب BC1 وBC2 من قيم الأبوين، مما أدى إلى انخفاض قيمـة قوة الهجين والتهجن عن قيم بـاقي الصفات وفي هذه الحالة فإن الانتخاب لا يكن كفوءاً لتماثل النباتـات وانمـا يفيدالتضـريب بـين السـلالات لايجـاد تغـايرات وراثية وانتاج هجين. الحالة نفسها حصلت لبقية التضرببات، نلاحظ من جدول 2 معنوبة التداخلات غير الاليلية وذلك مسن خـلال معنويـة A و B و C و التي اختلفت بـاختلاف التضريبات، فقد اظهرت التضريبات (FI01301×Rustico)

و (AntignaoHi39×Nostred) و تأثيراً سالبا لفعل الجين المضيف وغير معنوي ومنخفضا عن و قيمة m m (جدول ،3) مما يشير إلى قلة مساهمة فعل الجين المضيف في الصفة، فقط في التضريب( Rusticocanginix وجد تأثنر لفعل الجين المضيف موجبا ومعنويا الا
السيادي ×السيادي ويكون كلاهما معنويان. يمكن الافادة من

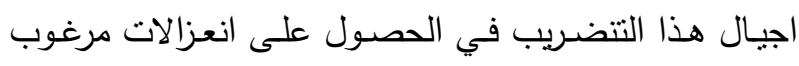

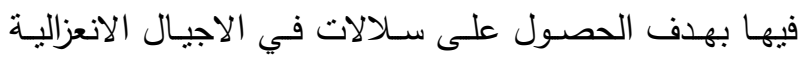

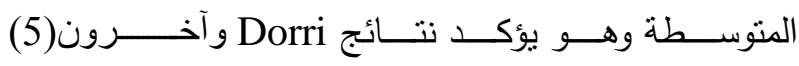
و Wannows وآخرون(30 ) . عدد حبوب النبات تفوق عدد حبوب النبـات للجيل الأول F1 على أبويـه لكل التضـريبات المستخدمة في هذا البحث ـ كذللك تفوق عدد حبوب النبات للجيل الثاني F2 و BC1 وBC2 على الأبوين دلالـة على عدم التماثلـل الوراثي للآبـاء بعبـارة اخرى وجـود

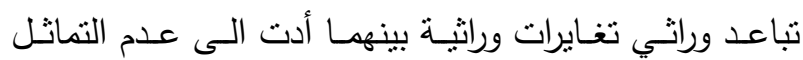
ويؤكد هذا قيم قوة الهجين والتهجن العالية مثتبـة وجود عدم

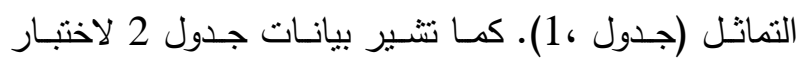
Scaling اختلفت بـاختلاف التضـريبات ولفهم التأثير غيـر الاليلي بصـورة أوضـح نجده في جدول 3 ،اذ ينبين فعل الجين المضيف المتحكم بهذه الصفة معنويا لكل التضريبات ألا انه سالبا باتجاه تقليل عدد حبوب النبات واقل من m m ـ يشير الى صـغر حجم مسـاهمة فعل الجين المضيف في توريـث


التضــريبات (FI01301×Rustico) و (Lo1391×Rustico) وغير معنوي في التضـربيين الآخرين .كمـا ان هذا التأثنير

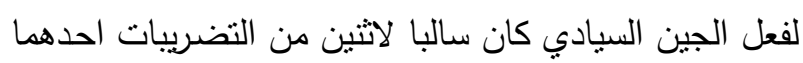

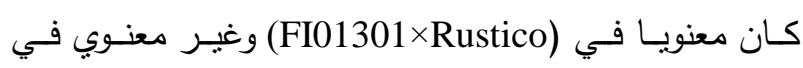
التضـريب. Rustico)




وهذا يشير إلى مساهمة كبيرة (AntignaoHi39×Nostred)

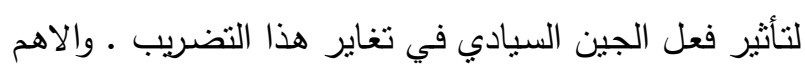

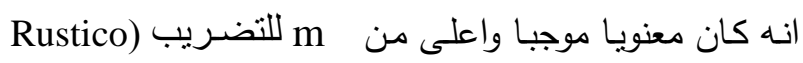

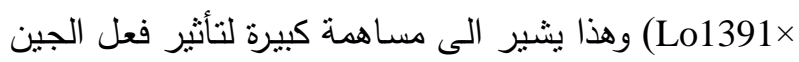
السيادي في تغاير هذا التضريب والذي تظهر اهميته في

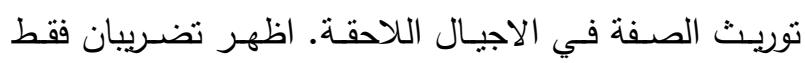

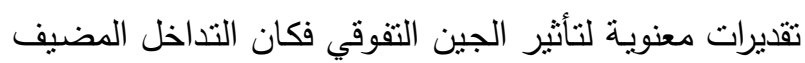

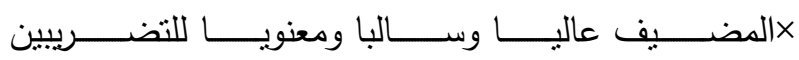
(Rusticocangini×Rustico) ， (FI01301×Rustico) وسالب غير معنوي للتضريب (AntignaoHi39×Nostred) 
كذللك فأن ارتفاع قيم BC1 وBC2 كلها تشير الى وجود تغاير وراثي في صفة الوزن الجاف لنبات الذرة الصفراء.

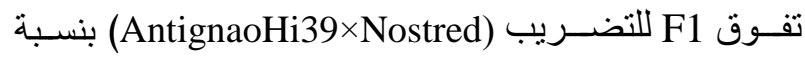


F2 و BC1 و BC2 كانت اعلى من الابـاء مشيرة الى تناثير

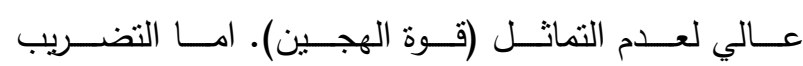
F1 فكان وزن النبات الجاف للذريـة (Lo1391×Rustico)

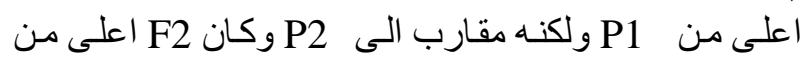
الابوين دلالة على وجود عدم تماثل الا ان عدم التماثل هذا

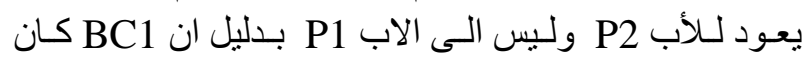



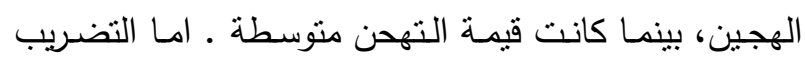



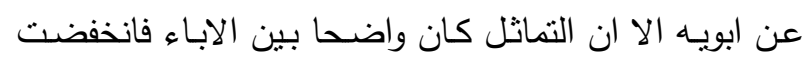
قوة الهجين والتهجن، وكذلك انخفاض قيمـة F2 عن الابـاء

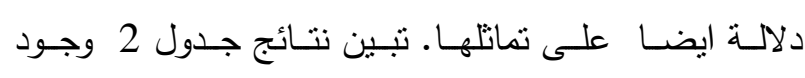

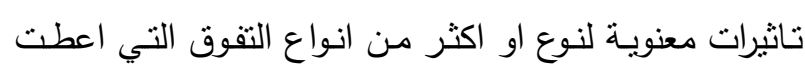

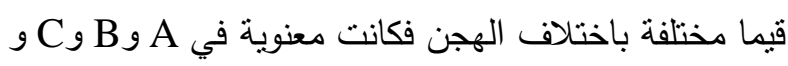

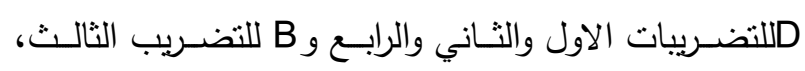
والتي نظهر اكثر تفصيلا في جدول 3 الذي نتير بياناته الى والى

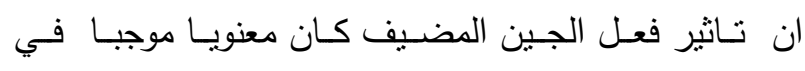


المتوسط الكلي m مؤكدة اسهاما قليلا لفعل الجين المضيف

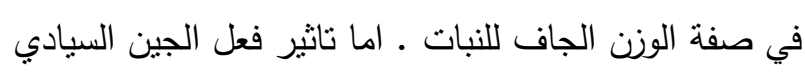

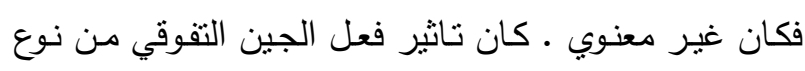

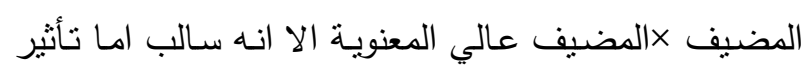
فعل الجين التفوقي من نوع السيادي × السيادي معنويا موجبا وعالي التأثثر في الصفة واعلى مـن كل التاثيرات السـابقة وحتى اعلى من قيمة m مشيرا الى سيطرة فعل الجين التفوقي


تحسين الصفة لهذا التضريب عن طريق انتاج الهجن وهذا

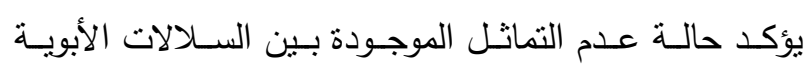

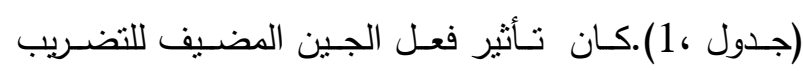
معنويــا سـالبا. امــا التـاثير (AntignaoHi39×Nostred) m السيادي للجين فكان معنويا موجبا وعاليا متفوقا على قيمة معندا. ومشيرا الى ان الصفة تقع تحت سيطرة فعل الجين السيادي



انه اقل من قيمة m مما يشير الى ضعف مساهمة فعل الجين المضيف في توريث صفة وزن الحبة لهذه التضريبات ففي حين كان تأثير فعل الجين السبادي موجبا ومعنويا في توري

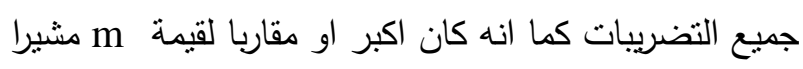

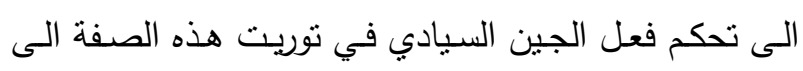

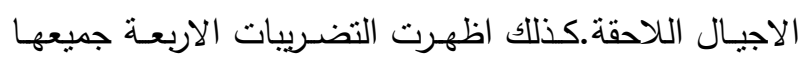

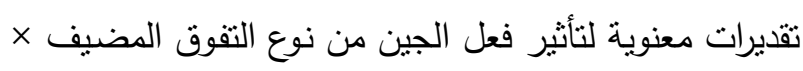
المضيف وكانت ثناث منها اعلى من قيم التضريب (Rusticocanginix Rustico) الذي كان اقل منه بقليل .اما التفوق من نوع المضيف × السبادي فكان معنويا



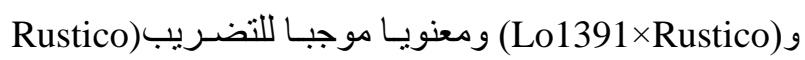

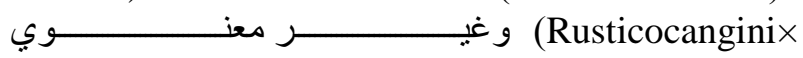

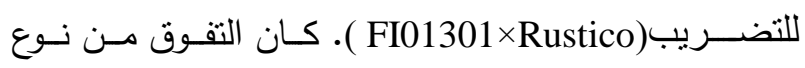

السيادي ×السيادي معنويـا سـالبا للتضـريب (Austico>


للتأثنير السيادي دلالة على وجود فعل جين متفوق من نوع


(Rusticocangini×Rustico)و (Lo1391×Rustico) وموجبا للتأثثر السيادي دلالة على وجود فعل جين متفوق من

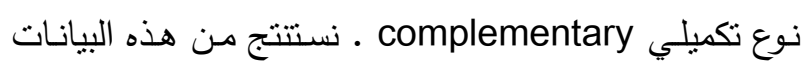
لهذه الصفة ان التضريبات اظهرت واحد اواكثر من اشكال التقديرات المعنوية لتأثير فعل الجين لتفوقي لواحد او اكثر من ان

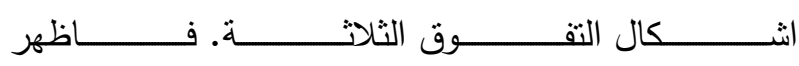

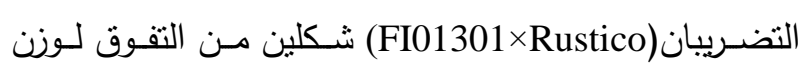

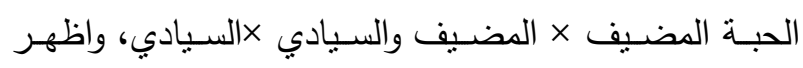

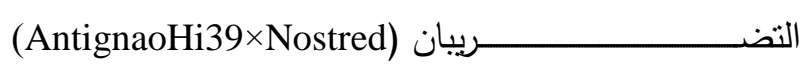

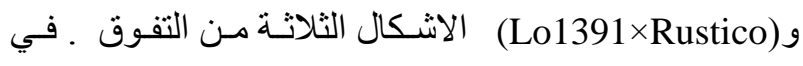
حين اظهر التضريب (Rusticocanginix Rustico) شكلين من التفوق المضيف ×المضيف والمضيف ×السيادي. وزن النبات الجاف يوضـح جدول 1 تفوق منوسط الوزن الجـاف للذربـة F1 في

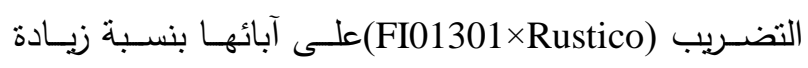
مقدارها 144.9\% عن الأب الأول و 85\% عن الاب الثاني وهذا ناتج من عدم التماثل بين الابوين الذي ادى الى ارتفاع


منوسط F2 كان مشابها للاب الثاني واعلى من الاب الاول 
يمكنتــا ملاحظتهـا مسن جـدول 3 الـــي يثــبر الـى وجـود اختلافات معنويـة موجبة لتأثنير فعل الجين المضيف الا انهـ كان اقل من قيمـة m وللتضريب (Lo1391×Rustico) وسالبة ومعنوية للتضريب (AntignaoHi39×Nostred) اما التضـريبات الاخرى فكـان تأثنير فعل الجين المضيف غير معنوي ـ في حين كان تأثنير فعل الجين السيادي معنويـا وعاليا للتضريب (Rusticocanginix Rustico) الا انه اقل من من قيمة m. كان تاثير فعل الجين السيادي للتضريب (AntignaoHi39×Nostred) $و($ FI01301×Rustico)


وهذا يشير الى ان الصفة تحت تاثير فعل الجين السيادي. امسا التضريب (Rusticocanginix Rustico) فكان تاثير فعل الجين السيادي غير معنوي .واضـح مـن جدول 3 ان التداخل الاليلي من نوع المضيف ×المضيف لم يكن معنويا

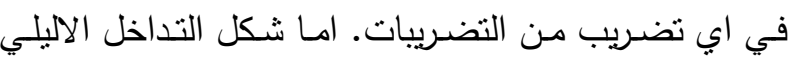

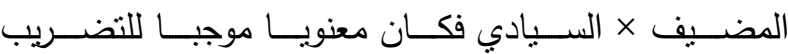
(Lo1391×Rustico)و

(AntignaoHi39 $\times$ Nostred) و (Rusticocangini×Rustico) الا انه اقل من m ، وتضريب (Ru (R)

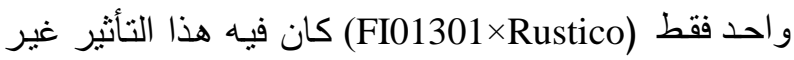

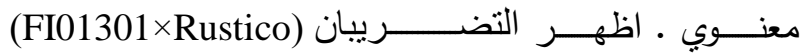


السيادي × السيادي موجبا ومعنويا واعلى من قيمة لالتة

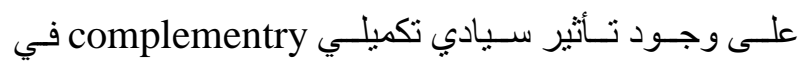
التحكم في الصفة امـا التضريب (Lo1391×Rustico) فكان شكل التفاعل الاليلي فيه معنويا سالبا ومقاربا لقيمة m و اظهر

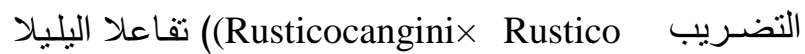

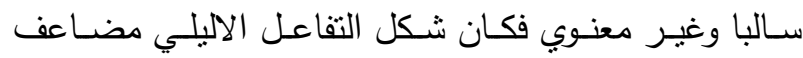
نسنتج من هذه البيانات عدم معنويـة التفاعل duplicate

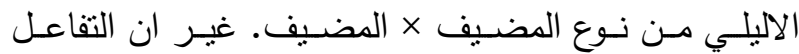
الاليلي مضيف × سيادي كان معنويا موجبا لنثلاث تضريبات

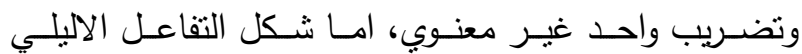

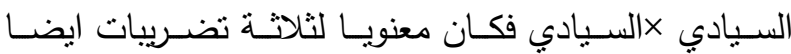
وتضريب واحد غير معنوي.
موجبا في نوع المضيف × المضيف وسالبا للنوعين الآخرين اظهـر التضـريب (Lo1391×Rustico) تـأثيرا معنويـا سـالبا

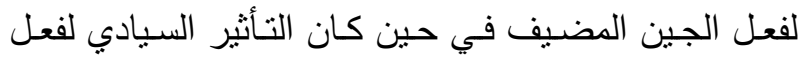
الجين غير معنوي. كذلك اظهر هذا التضريب شكلين من هنين




فكان معنويا سالبا واقل من قيمة m وهذا يشير إلى ان الآباء لم تصل الى مستوى كاف من homozygous لاظهار قوة

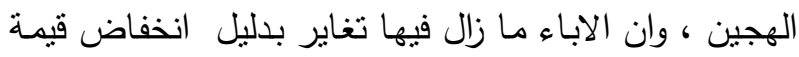


المضيف للتضريب Rusticocanginix Rustico معنويا وموجبا الا انه اقل من قيمة المتوسط الكلي الا ان تأثثير فعل معند

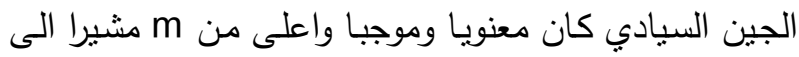
سبطرته في توريث هذه الصفة ، وقد اظهر هذا التضريب الاثكال الثنلاث من التفوق بصسورة معنويـة وموجبـة لتشكلين


الثالث من التفوق السيادي ×السيادي فالصفة محكومة بتأثير

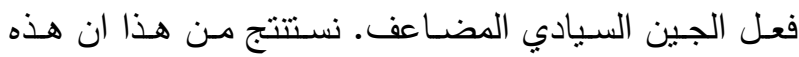

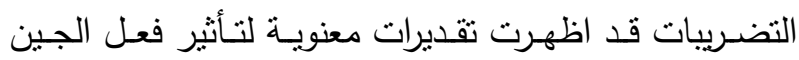
التفوقي لواحد او اكثر مـن اثتكال التفوق الثنلاتـة .فـاظهر

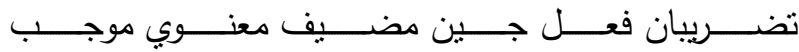
$و$ (FI01301×Rustico) و هـ امسا التضـريبان الاخران فكانـا (Rusticocangini×Rustico) سـالبين .امـا التـأثير السـيادي للجبين فكـان موجبـا معنويـا لتضـريبين وغير معنوي لتضـريبين اخـرين. امـا التفـاعلات الاليلية التفوقية فكانت معنوية سالبة لتضريب وموجبة دعنوية لتضـريبين وغير معنويـة لتضـريب اخر .امـا التفوق من نـوع المضيف xالسيادي فكان معنوي موجب لتضريبين ومعنوي سالب لتضريبين ـ كان التفوق من السيادي×السيادي سـالبا معتويل لتضريب وموجب لاخر وغير معنوي لاخر. حاصل الحبوب طن متري. هـ يوضح جدول 1 تفوق حاصل F1 على ابويه لكل التضريبات

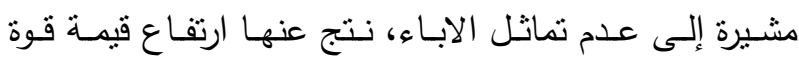

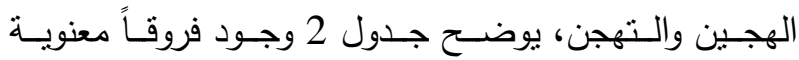
لناثثرات التفوق الاليلية وهي واضحة من معنوية كل من A




جدول 1. متوسطات الصفات مع أخطائها القياسية للأجيال الست لبعض تضريبات الذرة الصفراء وقوة الهجين والتهجن.

\begin{tabular}{|c|c|c|c|c|c|c|c|c|}
\hline Crosses & Generations & Ear length & No.rowslear & No.grainไrow & No.grainlplant & $\begin{array}{c}\text { Grain weight } \\
(\mathbf{1 0 0 )}\end{array}$ & $\begin{array}{c}\text { Dry weight } \\
\text { Iplant }\end{array}$ & $\begin{array}{c}\text { Grain } \\
\text { yield(tonไha) }\end{array}$ \\
\hline \multirow{8}{*}{ FI01301 $\times$ Rustico } & $\mathbf{P 1}$ & $15.42 \pm 0.14$ & $11.84 \pm 0.35$ & $21.66 \pm 0.29$ & $351.90 \pm 1.08$ & $24.54 \pm 0.43$ & $163.08 \pm 1.10$ & $5.07 \pm 0.15$ \\
\hline & $\mathbf{P 2}$ & $14.25 \pm 0.16$ & $13.09 \pm 0.16$ & $20.98 \pm 0.35$ & $382.06 \pm 3.96$ & $23.21 \pm 0.34$ & $215.75 \pm 3.04$ & $5.32 \pm 0.14$ \\
\hline & F1 & $20.63 \pm 0.17$ & $15.13 \pm 0.24$ & $37.69 \pm 0.31$ & $711.27 \pm 5.67$ & $27.87 \pm 0.29$ & $399.53 \pm 0.71$ & $11.8 \pm 0.39$ \\
\hline & F2 & $15.45 \pm 1.04$ & $12.00 \pm 0.91$ & $30.45 \pm 1.59$ & $495.72 \pm 65.99$ & $14.37 \pm 1.10$ & $215.93 \pm 9.52$ & $3.91 \pm 0.59$ \\
\hline & BC1 & $18.25 \pm 0.69$ & $13.00 \pm 0.54$ & $21.22 \pm 1.53$ & $226.35 \pm 6.83$ & $24.65 \pm 0.97$ & $163.72 \pm 1.79$ & $4.19 \pm 0.40$ \\
\hline & BC2 & $18.38 \pm 0.59$ & $16.20 \pm 0.45$ & $29.71 \pm 0.49$ & $253.82 \pm 2.99$ & $25.60 \pm 0.68$ & $148.38 \pm 2.12$ & $3.27 \pm 0.33$ \\
\hline & $\begin{array}{l}\text { Hybrid } \\
\text { vigor\% }\end{array}$ & 33.78 & 15.58 & 74.01 & 86.17 & 13.75 & 85.18 & 121.80 \\
\hline & Heterosis\% & 39.02 & 21.33 & 76.78 & 93.81 & 16.71 & 110.93 & 126.92 \\
\hline \multirow{8}{*}{ AntignaoHi3 $\times$ Nostred } & P1 & $14.84 \pm 0.17$ & $12.17 \pm 0.16$ & $19.92 \pm 0.08$ & $234.21 \pm 3.12$ & $22.98 \pm 0.13$ & $137.71 \pm 1.53$ & $5.07 \pm 0.15$ \\
\hline & $\mathbf{P 2}$ & $13.56 \pm 0.21$ & $14.00 \pm 0.41$ & $20.75 \pm 0.75$ & $297.19 \pm 4.47$ & $21.07 \pm 0.32$ & $129.43 \pm 3.42$ & $5.32 \pm 0.14$ \\
\hline & F1 & $17.94 \pm 0.12$ & $13.74 \pm 0.14$ & $29.95 \pm 0.21$ & $416.55 \pm 3.48$ & $26.32 \pm 0.21$ & $223.43 \pm 3.15$ & $11.63 \pm 0.40$ \\
\hline & F2 & $13.63 \pm 1.23$ & $13.50 \pm 0.74$ & $22.95 \pm 2.47$ & $467.14 \pm 50.57$ & $16.05 \pm 1.59$ & $137.03 \pm 8.42$ & $3.91 \pm 0.60$ \\
\hline & BC1 & $16.01 \pm 0.23$ & $12.50 \pm 0.50$ & $22.87 \pm 1.67$ & $331.40 \pm 6.46$ & $22.28 \pm 0.39$ & $194.20 \pm 4.59$ & $4.19 \pm 0.40$ \\
\hline & BC2 & $18.85 \pm 0.29$ & $14.63 \pm 0.47$ & $29.75 \pm 1.89$ & $431.87 \pm 32.12$ & $23.71 \pm 0.69$ & $247.81 \pm 2.42$ & $3.26 \pm 0.32$ \\
\hline & $\begin{array}{l}\text { Hybrid } \\
\text { vigor\% }\end{array}$ & 20.88 & -1.86 & 40.16 & 40.16 & 14.57 & 62.25 & 118.61 \\
\hline & Hetrosis\% & 26.33 & 4.96 & 47.25 & 56.77 & 19.47 & 67.28 & 123.65 \\
\hline \multirow{8}{*}{ Rustico $\times$ Lo1391 } & P1 & $13.58 \pm 0.34$ & $12.00 \pm 0.00$ & $16.00 \pm 0.41$ & $172.47 \pm 1.27$ & $26.45 \pm 0.21$ & $156.78 \pm 2.12$ & $2.67 \pm 0.06$ \\
\hline & $\mathbf{P 2}$ & $14.25 \pm 0.16$ & $13.09 \pm 0.16$ & $20.98 \pm 0.64$ & $382.09 \pm 0.92$ & $23.44 \pm 0.54$ & $243.99 \pm 1.17$ & $5.32 \pm 0.14$ \\
\hline & F1 & $20.90 \pm 0.21$ & $12.84 \pm 0.29$ & $34.63 \pm 0.47$ & $550.88 \pm 3.13$ & $25.72 \pm 0.25$ & $273.42 \pm 1.66$ & $8.50 \pm 0.12$ \\
\hline & F2 & $18.63 \pm 1.86$ & $14.13 \pm 1.39$ & $26.65 \pm 2.03$ & $428.73 \pm 31.20$ & $21.27 \pm 1.89$ & $276.41 \pm 42.82$ & $6.22 \pm 0.53$ \\
\hline & BC1 & $19.00 \pm 0.84$ & $12.75 \pm 0.32$ & $27.13 \pm 0.92$ & $382.91 \pm 7.40$ & $27.09 \pm 0.60$ & $210.29 \pm 6.96$ & $8.74 \pm 0.29$ \\
\hline & BC2 & $20.59 \pm 0.56$ & $14.84 \pm 1.17$ & $29.50 \pm 0.65$ & $589.48 \pm 11.69$ & $27.26 \pm 0.53$ & $356.32 \pm 5.12$ & $5.44 \pm 0.39$ \\
\hline & $\begin{array}{l}\text { Hybrid } \\
\text { vigor\% }\end{array}$ & 46.67 & -1.90 & 65.07 & 44.18 & -2.76 & 12.07 & 59.77 \\
\hline & Hetrosis\% & 0.50 & 2.32 & 74.89 & 98.67 & 3.09 & 36.44 & 113.04 \\
\hline \multirow{8}{*}{$\begin{array}{c}\text { Rusticocangin } \times \\
\text { Rustico }\end{array}$} & P1 & $16.09 \pm 0.16$ & $13.46 \pm 0.21$ & $24.00 \pm 0.58$ & $228.75 \pm 3.99$ & $26.01 \pm 0.67$ & $232.07 \pm 1.19$ & $3.57 \pm 0.311$ \\
\hline & $\mathbf{P 2}$ & $14.25 \pm 0.15$ & $13.09 \pm 0.16$ & $20.98 \pm 0.64$ & $381.32 \pm 3.22$ & $23.19 \pm 0.35$ & $243.99 \pm 1.17$ & $5.32 \pm 0.14$ \\
\hline & F1 & $21.53 \pm 0.39$ & $12.87 \pm 0.43$ & $36.56 \pm 0.86$ & $401.74 \pm 3.08$ & $27.98 \pm 0.59$ & $269.55 \pm 0.82$ & $6.75 \pm 0.25$ \\
\hline & F2 & $16.10 \pm 1.30$ & $14.35 \pm 0.87$ & $33.45 \pm 1.98$ & $512.02 \pm 20.01$ & $17.92 \pm 1.12$ & $151.97 \pm 4.80$ & $5.50 \pm 0.85$ \\
\hline & BC1 & $20.31 \pm 0.34$ & $13.50 \pm 0.20$ & $30.21 \pm 1.83$ & $420.75 \pm 10.49$ & $24.77 \pm 0.29$ & $263.81 \pm 2.81$ & $6.49 \pm 0.73$ \\
\hline & BC2 & $16.13 \pm 0.08$ & $14.35 \pm 0.17$ & $33.45 \pm 0.44$ & $514.86 \pm 5.70$ & $18.02 \pm 0.41$ & $195.70 \pm 3.69$ & $5.25 \pm 0.27$ \\
\hline & $\begin{array}{l}\text { Hybrid } \\
\text { vigor\% }\end{array}$ & 33.81 & -4.38 & 52.33 & 5.36 & 7.61 & 10.48 & 89.08 \\
\hline & Hetrosis\% & 41.92 & -3.08 & 62.92 & 31.70 & 13.74 & 13.12 & 51.68 \\
\hline
\end{tabular}


جدول2. اختبار Scaling للحاصل ومكوناته لبعض تضريبات الذرة الصفراء.

\begin{tabular}{|c|c|c|c|c|c|}
\hline Crosses & Traits & $\mathbf{A}$ & $\mathbf{B}$ & $\mathrm{C}$ & D \\
\hline \multirow{7}{*}{ FI01301×Rustico } & Ear Length (cm) & $0.45 \pm 1.42^{n . s}$ & $1.87 \pm 1.22^{\text {n.s }}$ & $-9.13 \pm 4.18 *$ & $-5.27 \pm 4.55^{\mathrm{n} . \mathrm{s}}$ \\
\hline & No. rows/ear & $-0.97 \pm 1.16^{n . s}$ & $4.19 \pm 0.95^{* *}$ & $-7.18 \pm 3.70^{*}$ & $-5.00 \pm 3.91^{n . s}$ \\
\hline & No. grains /row & $-16.93 \pm 3.09^{* * *}$ & $0.745 \pm 1.09^{n . s}$ & $3.77 \pm 6.43^{\text {n.s }}$ & $9.97 \pm 7.16^{*}$ \\
\hline & No. grains/plant & $-610.47 \pm 14.83^{* *}$ & $-585.69 \pm 9.14^{* *}$ & $-173.63 \pm 264.26^{n . s}$ & $510.14 \pm 264.17^{*}$ \\
\hline & Grain weight(100) & $-3.09 \pm 42.03^{n . s}$ & $0.128 \pm 1.43^{n . s}$ & $-46.02 \pm 4.48^{* *}$ & $-21.53 \pm 5.026^{* *}$ \\
\hline & Total dry matter & $-235.18 \pm 3.83^{* * *}$ & $-318.52 \pm 5.26 * *$ & $-314.17 \pm 38.25^{* *}$ & $119.76 \pm 38.499^{* *}$ \\
\hline & Grain yield(t/h) & $-8.51 \pm 0.91^{* *}$ & $-10.61 \pm 0.78^{* *}$ & $-18.42 \pm 2.53^{* *}$ & $-2.58 \pm 2.68^{n . s}$ \\
\hline \multirow{7}{*}{ AntignaoHi39× Nostred } & Ear Length (cm) & $-0.76 \pm 0.509^{n . s}$ & $6.19 \pm 0.622^{* *}$ & $-9.77 \pm 4.93^{*}$ & $-0.125 \pm 2.60^{n . s}$ \\
\hline & No. rows/ear & $-0.92 \pm 1.02^{n . s}$ & $1.50 \pm 1.04^{\text {n.s }}$ & $0.33 \pm 2.99^{\text {n.s }}$ & $0.83 \pm 3.32^{\text {n.s }}$ \\
\hline & No. grains /row & $-4.12 \pm 3.34^{n . s}$ & $8.79 \pm 3.85^{*}$ & $-8.78 \pm 9.91^{\mathrm{n} . \mathrm{s}}$ & $4.53 \pm 11.09^{n . s}$ \\
\hline & No. grains/plant & $12.04 \pm 13.74^{\text {n.s }}$ & $150.01 \pm 64.49^{*}$ & $504.06 \pm 202.46^{*}$ & $927.91 \pm 460.53^{*}$ \\
\hline & Grain weight(100) & $-4.74 \pm 0,81^{* * *}$ & $0.015 \pm 1.43^{\text {n.s }}$ & $-32.49 \pm 6.36$ *** & $-29.92 \pm 6.53^{*}$ \\
\hline & Total dry matter & $27.26 \pm 9.82^{* *}$ & $142.76 \pm 6.71^{* *}$ & $-165.88 \pm 34.46^{* *}$ & $-167.94 \pm 35.24^{* *}$ \\
\hline & Grain yield(t/h) & $-0.165 \pm 0.510$ & $2.78 \pm 1.25^{* *}$ & $-1.53 \pm 2.82^{n . s}$ & $-3.36 \pm 3.12^{n \cdot s}$ \\
\hline \multirow{7}{*}{ Lo1391 $\times$ Rustico } & Ear Length (cm) & $3.53 \pm 1.73^{*}$ & $6.03 \pm 1.16^{* *}$ & $4.88 \pm 7.46^{n . s}$ & $-2.33 \pm 7.73^{n . s}$ \\
\hline & No. rows/ear & $0.66 \pm 0.71^{n . s}$ & $3.75 \pm 2.35^{\text {n.s }}$ & $5.74 \pm 5.59^{\text {n.s }}$ & $0.65 \pm 6.21^{n . s}$ \\
\hline & No. grains /row & $3.63 \pm 1.93^{*}$ & $3.93 \pm 1.51^{*}$ & $0.37 \pm 8.23^{n . s}$ & $-3.32 \pm 8.44^{n . s}$ \\
\hline & No. grains/plant & $42.47 \pm 15.19^{* * *}$ & $245.99 \pm 23.61^{* *}$ & $58.59 \pm 124.97^{\text {n.s }}$ & $-114.95 \pm 127.54^{\mathrm{n} . \mathrm{s}}$ \\
\hline & Grain weight(100) & $2.02 \pm 1.25^{\mathrm{n} . \mathrm{s}}$ & $5.36 \pm 1.21^{* *}$ & $-16.26 \pm 7.59^{*}$ & $-11.82 \pm 7.7^{\text {n.s }}$ \\
\hline & Total dry matter & $-9.60 \pm 14.17^{\text {n.s }}$ & $195.22 \pm 10.44^{* *}$ & $158.02 \pm 171.33^{\text {n.s }}$ & $-13.81 \pm 172.15^{n . s}$ \\
\hline & Grain yield(t/h) & $6.30 \pm 0.59^{* * *}$ & $-2.94 \pm 0.79^{* * *}$ & $-0.135 \pm 2.13^{n . s}$ & $-1.74 \pm 2.23^{n . s}$ \\
\hline \multirow{7}{*}{ Rusticocangini× Rustico } & Ear Length $(\mathrm{cm})$ & $3.01 \pm 0.80^{* *}$ & $-3.52 \pm 0.44^{* *}$ & $-8.99 \pm 5.23^{n . s}$ & $-4.24 \pm 5.21^{\mathrm{n} . s}$ \\
\hline & No. rows/ear & $0.66 \pm 0.62^{\text {n.s }}$ & $2.73 \pm 0.57^{* *}$ & $5.10 \pm 3.61^{\text {n.s }}$ & $1.37 \pm 3.53^{. s}$ \\
\hline & No. grains /row & $-0.135 \pm 3.82^{n . s}$ & $9.37 \pm 1.38^{* *}$ & $15.72 \pm 8.16^{*}$ & $3.24 \pm 8.90^{\text {n.s }}$ \\
\hline & No. grains/plant & $211.02 \pm 21.59^{* * *}$ & $246.66 \pm 12.24^{* *}$ & $634.55 \pm 80.43^{* *}$ & $88.43 \pm 83.533^{* *}$ \\
\hline & Grain weight(100) & $-4.45 \pm 1.06^{* * *}$ & $-15.13 \pm 1.07^{* * *}$ & $-33.46 \pm 4.69^{* *}$ & $-6.94 \pm 4.5^{*}$ \\
\hline & Total dry matter & $25.99 \pm 5.81^{* *}$ & $-122.15 \pm 7.52^{* *}$ & $-407.28 \pm 19.33^{* * *}$ & $155.57 \pm 21.32^{* *}$ \\
\hline & Grain yield(t/h) & $2.67 \pm 1.52^{*}$ & $-1.57 \pm 0.60^{* *}$ & $-0.39 \pm 3.45^{n . s}$ & $0.74 \pm 3.82^{\text {n.s }}$ \\
\hline
\end{tabular}


جدول 3. التحليل الوراثي لمتوسط الأجيال وأخطائها القياسية وتقدير المعالم الوراثية للحاصل ومكوناته لبعض تضريبات الذرة الصفراء.

\begin{tabular}{|c|c|c|c|c|c|c|c|c|}
\hline Crosses & Traits & $\mathbf{m}$ & [d] & [h] & [i] & [j] & {$[\mathrm{l}]$} & type of epistais \\
\hline \multirow{7}{*}{ FI01301×Rustico } & Ear Length (cm) & $15.45 \pm 1.04^{* * *}$ & $-0.125 \pm 0.92^{n . s}$ & $17.25 \pm 4.56 *$ & $11.45 \pm 4.55^{*}$ & $-0.71 \pm 0.93^{n . s}$ & $-13 . .76^{*}$ & Duplicate \\
\hline & No. rows/ear & $12.00 \pm 0.91^{* *}$ & $-3.20 \pm 0.71^{* *}$ & $13.06 \pm 3.92^{* *}$ & $10.40 \pm 3.91^{* *}$ & $-2.58 \pm 0.73^{* *}$ & $-13.62 \pm 4.65^{* *}$ & Duplicate \\
\hline & No. grains /row & $30.45 \pm 1.59^{* *}$ & $-8.49 \pm 1.60^{* * *}$ & $-3.57 \pm 7.16^{n . s}$ & $-19.95 \pm 7.14^{* *}$ & $-8,83 \pm 1.62^{* * *}$ & $36.13 \pm 9.09^{* * *}$ & \\
\hline & No. grains/plant & $495.72 \pm 65.99^{* *}$ & $-27.47 \pm 7.46^{* *}$ & $-678.24 \pm 264.47^{*}$ & $-1022.53 \pm 264.40^{* * *}$ & $-12.39 \pm 7.73^{\text {n.s }}$ & $2218.68 \pm 8.34^{* * *}$ & Duplicate \\
\hline & $\begin{array}{c}\text { Grain } \\
\text { weight(100) }\end{array}$ & $14.37 \pm 1.10^{* * *}$ & $-0.94 \pm 1.19^{n . s}$ & $47.05 \pm 5.03^{* *}$ & $43.06 \pm 5.02^{* *}$ & $-1.61 \pm 1.22^{n . s}$ & $-40.09 \pm 6.54^{* *}$ & Duplicate \\
\hline & Total dry matter & $215.93 \pm 9.52^{* * *}$ & $15.33 \pm 2.78^{* * *}$ & $-29.41 \pm 38.53^{\text {n.s }}$ & $-239.53 \pm 38.49^{* * *}$ & $41.67 \pm 3.21^{* * *}$ & $793.23 \pm 39.84^{* * *}$ & \\
\hline & Grain yield(t/h) & $3.91 \pm 0.60 * *$ & $0.92 \pm 0.52^{\text {n.s }}$ & $5.93 \pm 2.65^{*}$ & $-0.70 \pm 2.61 n . s$ & $1.05 \pm 0.53^{\text {n.s }}$ & $19.83 \pm 3.27^{* *}$ & complementary \\
\hline \multirow{7}{*}{$\begin{array}{l}\text { AntignaoHi39x } \\
\text { Nostred }\end{array}$} & Ear Length $(\mathbf{c m})$ & $13.63 \pm 1.23^{* * *}$ & $-2.84 \pm 0.37^{* *}$ & $18.94 \pm 4.98^{* * *}$ & $15.21 \pm 4.97^{* * *}$ & $-3.47 \pm 0.39^{* *}$ & $-20.64 \pm 5.15^{* *}$ & Duplicate \\
\hline & No. rows/ear & $13.50 \pm 0.74^{* * *}$ & $-2.13 \pm 0.68^{* * *}$ & $0.92 \pm 3.26^{\text {n.s }}$ & $0.25 \pm 3.25^{\text {n.s }}$ & $-1.21 \pm 0.72^{\text {n.s }}$ & $-0.83 \pm 4.07^{n . s}$ & \\
\hline & No. grains /row & $22.95 \pm 2.74^{* *}$ & $-6.87 \pm 2.52^{* *}$ & $23.07 \pm 11.10^{*}$ & $13.46 \pm 11.09^{n . s}$ & $-6.48 \pm 2.55^{*}$ & $-18.14 \pm 14.14^{n . s}$ & \\
\hline & No. grains/plant & $467.14 \pm 50.57^{* *}$ & $-100.47 \pm 32.77^{* *}$ & $191.16 \pm 212.67^{\text {n.s }}$ & $-342.01 \pm 212.67^{n . s}$ & $-68.98 \pm 32.88^{*}$ & $179.97 \pm 241.19^{\text {n.s }}$ & \\
\hline & $\begin{array}{c}\text { Grain } \\
\text { weight (100) }\end{array}$ & $16.05 \pm 1.58^{* * *}$ & $-1.43 \pm 0.80 n . s$ & $32.06 \pm 6.533^{* *}$ & $27.77 \pm 6.52^{* *}$ & $-2.37 \pm 0.81^{* *}$ & $-23.04 \pm 7.10^{* * *}$ & Duplicate \\
\hline & Total dry matter & $137.03 \pm 8.42^{* * *}$ & $-53.61 \pm 5.19^{* *}$ & $425.77 \pm 35.43^{* *}$ & $335,89 \pm 35.24^{* *}$ & $-57.75 \pm 5.51^{* *}$ & $-505.92 \pm 40.22^{* *}$ & Duplicate \\
\hline & Grain yield(t/h) & $4.35 \pm 0.68^{* * *}$ & $-1.77 \pm 0.60 * *$ & $6.58 \pm 3.01^{*}$ & $-4.14 \pm 2.99^{n \cdot s}$ & $1.47 \pm 0.66^{*}$ & $6.76 \pm 3.77^{*}$ & complementary \\
\hline \multirow{7}{*}{$\begin{array}{c}\text { Lo1391 } x \\
\text { Rustico }\end{array}$} & Ear Length $(\mathrm{cm})$ & $18.63 \pm 1.86^{* * *}$ & $-1.59 \pm 1.02^{\text {n.s }}$ & $11.67 \pm 7.72^{\text {n.s }}$ & $4.68 \pm 7.71^{\text {n.s }}$ & $-1.25 \pm 1.03^{\text {n.s }}$ & $-14.23 \pm 8.50^{n . s}$ & \\
\hline & No. rows/ear & $14.13 \pm 1.39^{* * *}$ & $-2.09 \pm 1.21^{n . s}$ & $-1.04 \pm 6.07^{n . s}$ & $-1.33 \pm 6.06^{n . s}$ & $-1.54 \pm 1.21^{n . s}$ & $-3.08 \pm 7.40^{\text {n.s }}$ & \\
\hline & No. grains /row & $26.65 \pm 2.04^{* * *}$ & $-2.38 \pm 1.12^{*}$ & $22.79 \pm 8.47^{* *}$ & $6.65 \pm 8.45^{\text {n.s }}$ & $0.12 \pm 1.18^{\text {n.s }}$ & $-13.67 \pm 9.37^{\text {n.s }}$ & Duplicate \\
\hline & No. grains/plant & $428.73 \pm 31.20^{* *}$ & $-206.57 \pm 13.84^{* *}$ & $503.49 \pm 127.87^{* *}$ & $229.86 \pm 127.83^{\text {n.s }}$ & $-101.76 \pm 13.86^{* *}$ & $-518.36 \pm 136.68^{* *}$ & Duplicate \\
\hline & $\begin{array}{c}\text { Grain } \\
\text { weight }(100)\end{array}$ & $21.27 \pm 1.89^{* * *}$ & $-0.17 \pm 0.80 n . s$ & $24.42 \pm 7.73^{* *}$ & $23.64 \pm 7.72^{* * *}$ & $-1.67 \pm 0.86^{*}$ & $31.02 \pm 8.24^{* *}$ & Complementary \\
\hline & Total dry matter & $276.41 \pm 42.82^{* * *}$ & $-146.02 \pm 8.64^{* *}$ & $100.63 \pm 172.16^{\text {n.s }}$ & $27.61 \pm 172.15^{\text {n.s }}$ & $-102.41 \pm 8.72^{* * *}$ & $-213.23 \pm 174.78^{n . s}$ & \\
\hline & Grain yield(t/h) & $6.22 \pm 0.53^{* *}$ & $3.30 \pm 0.48^{* *}$ & $7.99 \pm 2.32^{* *}$ & $3.49 \pm 2.31^{\text {n.s }}$ & $4.63 \pm 0.49^{* *}$ & $-6.85 \pm 2.86^{*}$ & Duplicate \\
\hline \multirow{7}{*}{$\begin{array}{c}\text { Rusticocanginix } \\
\text { Rustico }\end{array}$} & Ear Length $(\mathrm{cm})$ & $16.10 \pm 1.29^{* * *}$ & $4.19 \pm 0.35^{* *}$ & $14.83 \pm 5.23^{* *}$ & $8.48 \pm 5.21^{\text {n.s }}$ & $3.26 \pm 0.37^{* *}$ & $-7.96 \pm 5.42^{\text {n.s }}$ & \\
\hline & No. rows/ear & $14.35 \pm 0.87^{* * *}$ & $-0.85 \pm 0.27^{* *}$ & $-2.10 \pm 3.56^{n . s}$ & $1.70 \pm 3.53^{\text {n.s }}$ & $-1.04 \pm 0.30^{* * *}$ & $-1.70 \pm 3.76^{n \cdot s}$ & \\
\hline & No. grains /row & $33.45 \pm 1.98^{* *}$ & $-3.24 \pm 1.89^{\text {n.s }}$ & $7.59 \pm 8.84^{\text {n.s }}$ & $-6.48 \pm 8.79^{n . s}$ & $-4.75 \pm 1.93^{*}$ & $-2.76 \pm 11.12^{\mathrm{n} . s}$ & \\
\hline & No. grains/plant & $512.02 \pm 20.01^{* *}$ & $-94.10 \pm 11.95^{* *}$ & $-80 \pm 83.62^{\text {n.s }}$ & $-176.88 \pm 83.52^{*}$ & $-17.82 \pm 12.21^{\mathrm{n}, \mathrm{s}}$ & $-280 \pm 93.56$ & \\
\hline & $\begin{array}{c}\text { Grain } \\
\text { weight(100) }\end{array}$ & $17.92 \pm 1.12^{* * *}$ & $6.74 \pm 0.50^{* *}$ & $17.27 \pm 4.64^{* *}$ & $13.89 \pm 4.59^{* *}$ & $5.34 \pm 0.63^{* * *}$ & $5.68 \pm 5.10^{n . s}$ & \\
\hline & Total dry matter & $151.97 \pm 4.80$ & $68.11 \pm 4.64^{* *}$ & $342.65 \pm 21.35^{* * *}$ & $311.14 \pm 21.32^{* * *}$ & $74.07 \pm 4.72^{* *}$ & $-214.98 \pm 26.81^{* *}$ & Duplicate \\
\hline & Grain yield(t/h) & $5.49 \pm 0.85^{* *}$ & $1.24 \pm 0.78^{\text {n.s }}$ & $3.80 \pm 3.76^{\text {n.s }}$ & $1.51 \pm 3.74^{\text {n.s }}$ & $2.12 \pm 0.80^{* *}$ & $-2.62 \pm 4.65^{n . s}$ & \\
\hline
\end{tabular}




\section{REFERENCES}

1.Akbar,M.,M.Saleem,F.M.Azhar,M.Y.Ashraf and R.Ahmed.2008.Combining ability analysis in maize under normal and high temperature condition .J of Agric Res 46(1):27-38.

2.Alam,A .K.M., S. Ahmed, M. Begum, and M.K.Sultan.2008. Hetrosis and combining ability for grain yield and its contributing characters in maize .BangladeshJ.of Agric .Res 33(3):375-379

3. Al Hadi , R . A ., M . Sabbouh and S. AlAhmad .2013.Genetic analysis of some traits in segregation generation of two maize (Zea maysL.) hybrids. Damascus Journal of Agriculture Sciences. 29(2) :117-135. 4.Aziz,F., A. M. Rezai,G. Saeidi. 2006. Generation mean analysis to estimate genetic parameters for different traits in two crosses of corn inbred lines at three planting densities.J. Agric. sci. Technol8(2):153-169.

5. Dorri, P. ,S. K. Khorasani and M.Shahroki. 2014.Generation Mean Analysis:Acase study of variance components in KSC500 generation of maize (Zea mays L.). International Research .J. of Applied and Basic Sciences. 8(2) :194200 .

6. Gambel, F.F. 1962. Gene effects in corn (Zea mays L.). I. Separation and relative importance of gene effects for yield. Candian J. Plant sci.42:339-348.

7. Hallauer, A. R., and J.B.Miranda .1988. Quantitative Genetics In Maize Breeding $2^{\text {nd }}$. Iowa state Univ. press. Ames. IA. USA. PP:367.

8.Haq, M. I. U, S. Ajma 1, N. Kamal, S. Khanum, M. Siddique and M. Z. kiani. 2013. Generation Mean Analysis for grain yield in maize . The Journal of Animal \&Plant Sciences, 23(4):1146-1151.

9.Hinz,L.L., and K.R.Lamkey.2003.Absence of epistasis for grain yield in elite maize hybrids. Crop Sci.43:46-56

10.Iqbal, K. K., H. Rahman, and H. Sher. 2010. Detection of epistasis for plant height and leaf area per plant in maize (Zea mays L.) from generation mean analysis . Maydica 55:33-39.

11.Ketate, H ., E.L.,Smith, L.H. Edward, and R.W. McNew.1976. Detection of epistasis ,additive, and dominance variation in winter wheat (Triticum aestivum .emThell) .Crop Sci. 16:1-4.

12. Kumar, A. , M. Ganshett and G. Kumar. 1998. Gene effects in some traits of maize (Zea mays L.)Annals of Agriculture Biologi cal Research.3(2):139-143.

13.Kumar, R. ,M. Sing, M. S. Narwal and S. Sharma .2005.Gene effects for grain yield and its attributes in maize (Zea mays L.). National J. of plant Improvement 7(2):105-107.

14. Mather, K. and J.L.Jinks.1982.Biometrical Genetic .Methuen,London,pp:162.

15.Melchinger, A. E. ,M. Lee, K. R. Lamky, A. R . Hallauer and W. L. Woodman . 1990. Genetic diversity for restrication fragment length poly morphisms and heterosis for tow diallelsets of maize inbreds. Theoretical and Applied Genetic. 80:488-496.

16.Muraya, M. M. ,C. M. Ndiraugu and E. O. Omolo. 2006. Hetrosis and combining ability diallel crosses involving maize (Zea mays L.) $\mathrm{S}_{1}$ lines. Australian J. of Expermental Agriculture 46(3) :387-394 .

17. Ravikant Prase,R . C. 2006. Gene effects for metric traits in quality protein maize (QPM)(Zea maysL.) . Crop Improvement J.33:94-101.

18.Rezaei, A. H. and V. Roohi.2004. Estimation of genetic parametersin corn(Zea mays) based on diallel crossing system . New direction for diverse plant. proceeding of the 4 th International Crop Science congres,26 Septmber-October-Brisbane

,Australia.PP:235.

19.Rita, H . M . 2007. Backcross versus forward breeing in the development of transgenic maize hybrid : Theory and practice. Crop. Sci (47):164-171.

20.Saleem, M. ,K. ,sh,M. Jared and A. Ahmed. 2002. Genetic analysis for various quantitative traits in maize (Zea mays L.) inbred lines International Journal of Agricultural Biology.4:379-382.

21.Shahrokhi, M. ,S. K. Khorasani, and A. Ebrahimi. 2011 .Generation mean analysis for yield and yield component in maize (Zea mays L.). Journal of Plant Physiology and Breeding.1(2):59-72.

22.Sher, H. ,M. Iqbal. ,K. Khan, M. Yasir and H. Ur. Rahman .2012.Genetic analysis of 
maturity and flowering characteristies in maize (Zea mays L.) Asian procific J. Tropical Biomedicine :621-626.

23.Sing, P.K., and A.K.Roy.2007. Diallel analysis of inbred lines in maize(Zea mays L.) Intl.J.Agri.Sci.3:213-216.

24.Sing, R. K. , and B. D. Chaudhary. 1985. Biometrical Methods in Quantitative Genetic Analysis . Kalyani publishers, New Delhi,Ludhiana.pp.318.

25.Sing, R. P. and S. Sing .1992.Estimation of genetic parameter through generation mean analysis in bread wheat. Indian Journal of Genetics.52:369-375.

26.Srdic,J.,Z. Pajic and S.S.MladenovicDrinie.2007.Inheritance of maize grain yield components.Maydica 52 (3):261-264.
27.Unay, A. ,H. Basal, and C. Knonak. 2004. Inheritance of grain yield in a half-diallel maize population .TurkJ.Agric.28:239-244. 28.Vidal- Martienz, V. A ., M. Clegg, B. Johnson, and R. Valdivia -Bernal . 2001. Phenotypic and genotypic relationship between pollen and grain yield components in maize. Agrociencia. 35:503-511.

29.Wannows , A. A., M. Y. Sabbouh and S. A. AL-Ahmed. 2015. Generation means analysis technique for determining genetic parameters for some quantitative traits in two maize hybrids (Zea mays L.) . Jordon Journal of Agric Sciences.11(1):59-73.

30.Wolf, D.P., and A.R.Hallauer.1977.Triple test analysis to detect epistasis in maize ..Crop Sci.37:763-770. 